\title{
MODULATION INDEX AND SWITCHING FREQUENCY EFFECT ON SYMMETRIC REGULAR SAMPLED SPWM
}

\author{
Mehmet Emin ASKER ${ }^{I}$, Heybet KILIÇ \\ ${ }^{1}$ Vocational Schools of Technical Sciences, Dicle University, Diyarbakir, Turkey \\ *Corresponding author; heybetkilic@ hotmail.com
}

Inverter, is an electronic device or circuitry that changes direct current $(D C)$ to alternating current $(A C)$. The output voltage and frequency of the inverter can be changed. There are different modulation methods used in inverter control. Some of these methods can be applied digitally, some analogously. Classical Sinusoidal Pulse Width Modulation (SPWM) is a method normally performed analogously. Known methods for digitally applying this method are regular sampled sinusoidal PWM methods. In this study, the implementation of symmetric regular sampled sinusoidal PWM method is discussed. Two fundamental factors that are effective in this kind of modulation methods are investigated by harmonic analysis of switching frequency and modulation index, inverter pole voltage and line voltage. From an inverter that supplies a three-phase RL load, the fundamental component and the generated harmonics are investigated using the Symmetric Regular Sampled SPWM method with five different switching frequencies and three different modulation index values. Modulation index is investigated for linear region and over modulation regions. Low, normal and high switching frequency samples are also chosen for switching frequency. The obtained harmonic analysis results are presented in the study.

Index Terms: Modulation index, Switching frequency, Inverter, Symmetrical regular sampled SPWM

\section{Introduction}

The easiest and most economical way to obtain a sinusoidal voltage is pulse width modulation (PWM). In the PWM method, the input amplitude is kept constant, but the amplitude of the pulse or the duration of the pulse is modulated according to the desired sinusoidal output at the output. The PWM waveform can be obtained in different forms[1].

To perform SPWM method, a sinusoidal wave is obtained by sampling sinusoidal wave, positive or negative and positive peak values of the carrier wave. This stepped wave is digitally compared to a triangular wave. In this method, if the sampling is performed in the switching period (carrier wave positive peak values), the symmetric regular sampled SPWM is defined as asymmetric regular sampled SPWM. In case of performing in half of the switching period (carrier wave both positive and negative peak values)[2-4]. 
With the SPWM method, the output voltage at the linear region can be increased by a certain value ( $\mathrm{Vd} / 2)$ ( $78.5 \%$ of the inverter capacity). To increase this value, the output voltage can be increased more $(90.7 \%)$ by the third harmonic added PWM method which is developed by adding third harmonic to the reference sine wave. In this case, however, a large third harmonic appears at the pole voltage [5].

The switching frequency has an effect on the switching elements of the inverter. Switching frequency selection affects acoustical noise, harmonic content, transmission loss and transmission noise of switching elements [6-7]. It is important to select the most appropriate switching frequency depending on the tune. The modulation index is known as square wave at zero, linear variation at $(0-$ 1), and 1 denominator over modulation region [8]. In this study, investigations were carried out for the linear region and over-modulation region.

The harmonic analysis is valuable to study harmonic components of output line voltage and pole voltage. The switching frequency and the harmonics occurring in the folds and the side folds give a good idea for the analysis [9-10].

\section{Conventional Sinusoidal PWM (SPWM)}

In this method, a reference sinusoidal wave to be obtained at the output is compared with a carrier triangular wave at the switching frequency to produce pulses at the intersection points. The principle scheme is shown in figure 3.1. The fundamental voltage component and frequency of the PWM wave are controlled by the reference wave amplitude and frequency $[1,3]$.

In the comparison process, if the reference wave is greater than the carrier wave, the upper key in the inverter bass is in the transmission, the sub-key is in the cut-off, and vice versa. As shown in Figure 3.1, the summation of the key transmission and the cut-off period is equal to the carrier wave period $[1,8]$

The reference sinusoidal wave signal having the control signal, the amplitude $V_{\text {cont }}$ frequency $f$, the carrier wave signal amplitude $V_{t}$, and the frequency $f_{s}$.

The ratio of the reference wave amplitude to the triangular wave amplitude is called the amplitude modulation ratio $\left(\mathrm{m}_{\mathrm{a}}\right)$ or modulation index.

$m_{a}=\frac{V_{\text {cont }}}{V_{t}}$

The ratio of the carrier wave frequency to the control signal frequency is defined as the frequency modulation rate $\left(\mathrm{m}_{\mathrm{f}}\right)$.

$m_{f}=\frac{f_{s}}{f}$

\subsection{The Importance of the Modulation Index $\left(\mathbf{m}_{\mathbf{a}}\right)$}

At $\mathrm{m}_{\mathrm{a}}=0$, a square wave forms at the switching frequency. At $\mathrm{m}_{\mathrm{a}}=1$ the basic component takes $0.5 \mathrm{Vd}$. This value, which is the maximum value for the linear region, corresponds to $78.55 \%$ of the square wave state, $\left(\frac{4}{\pi} \frac{V d}{2}\right)$ which is the maximum value that the inverter can generate [11].

There are three important states of the modulation index value for $m_{a} \leq 1$, that is, for the linear region [3]. First, the first harmonic $\left(V_{A o}\right)$ of the output voltage in the linear region with $0 \leq m_{a} \leq 1$ varies linearly with $1 m_{a}$.

$$
\left(\hat{V}_{A o}\right)_{1}=m_{a} \frac{V d}{2} \quad m_{a} \leq 1.0
$$


The second occurs in the form of harmonics switching frequency $\left(f_{s}\right)$ and its folds $m_{f}, 2 m_{f}, 3 m_{f}$, $\ldots$, in the inverter output voltage ripple.

$$
\begin{aligned}
& f_{h}=\left(j m_{f} \underline{+k}\right) f_{1} \\
& h=j\left(m_{f}\right) \underline{+k}
\end{aligned}
$$

The third order $h$ is the harmonic order; For odd values of $J$, the harmonics occur at odd values of $k$, for odd values of $j$, at odd values of $k$. That is, the side harmonics $m_{f}-2, m_{f}-4 ; \ldots, 2 m_{f}-1,2 m_{f}$ $5 ; \ldots, 3 m_{f}-2,3 m_{f}-4 ; \ldots, 4 m_{f}-1,4 m_{f}-5 ; \ldots . .[3,12]$.

$m_{f}$ must be a odd and an integer. When $m_{f}$ odd and integer are selected, both single-function symmetry and half-wave symmetry are used. In this case, there are only one harmonics [3].

\subsection{Switching Frequency and Frequency Modulation Ratio $\left(m_{f}\right)$ Selection.}

Since the high frequency voltage harmonics are easier to filter, it is desirable to set the switching frequency as high as possible. In this case, however, inverter switching losses increase. Therefore, the switching frequency is selected as small as $6 \mathrm{kHz}$ or $20 \mathrm{kHz}$ as the frequency that the human ear can operate. For values of the switching frequency not exceeding $2 \mathrm{KHz}, m_{f}$ is selected as a value of 9 or below. $m_{f}=21$ is regarded as the limit value for whether $m_{f}$ is large or small for the values of $1 \min$ of $m_{a}$ [3].

There are two methods for selecting the carrier waveguide for fundamental frequency control. The first one is Asynchrony PWM. In this method, the carrier wave frequency is fixed, and the frequency of the modulation wave is changed. In this case, lower harmonics are formed in the inverter output voltage ripple, which is smaller than the fundamental frequency. It is appropriate to use this method because the lower harmonics that occur in the large values of mf for $m_{a}>1$ are quite small. The second is the synchronous PWM method in which the reference wave and the carrier wave synchronize. In synchronous PWM, the carrier wave frequency is set to be $m_{f}$ integer. Synchronous PWM should be applied when $m_{f}$ is small $[3,4]$.

\section{Types of Sinusoidal PWM}

The sinusoidal PWM method is investigated in two parts in terms of its implementation [4]. Classical sinusoidal pulse width modulation is SPWM with natural sampling.

\subsection{Natural Sampling SPWM}

Analogous implementation of the sinusoidal PWM method is called natural sampling sinusoidal PWM. A triangular carrier wave is compared with the reference sine wave at the desired output frequency to obtain the switching signals of the semiconductor element. The amplitude of the reference sine is changed to change the amplitude of the output voltage.

\subsection{Regular Sampled SPWM}

It can be described as the digital realization of sinusoidal PWM. It is numerical in nature and suitable for digital hardware and microprocessor applications. Here, the sinusoidal modulation wave is sampled at regular intervals in accordance with the positive peaks of the synchronous carrier or both positive and negative peaks. Maintain the "Sample and Hold Circuit" constant until a new sample is acquired. With this operation, the reference circuit becomes stepped and becomes modulated in amplitude. This stepped wave is digitally compared with a triangular carrier wave, and the cut-off points determine the inverter switching moments. This technique is known as regular sampled sinusoidal PWM [2].

The sinusoidal PWM method with regular sampling is examined in two parts as symmetric regular sampled and asymmetric regular sampled sinusoidal PWM [4]. 


\subsubsection{Symmetric Regular Sampled SPWM}

Sampling is carried out at carrier peak positive peaks, at the switching frequency. The carrier wave is digitally compared to the sampled wave sine in the switching period. This method is called symmetric regular sampled SPWM because the sine wave impulse and the triangular wave intersection are symmetric. The pulse width is dependent on the modulation index [4].

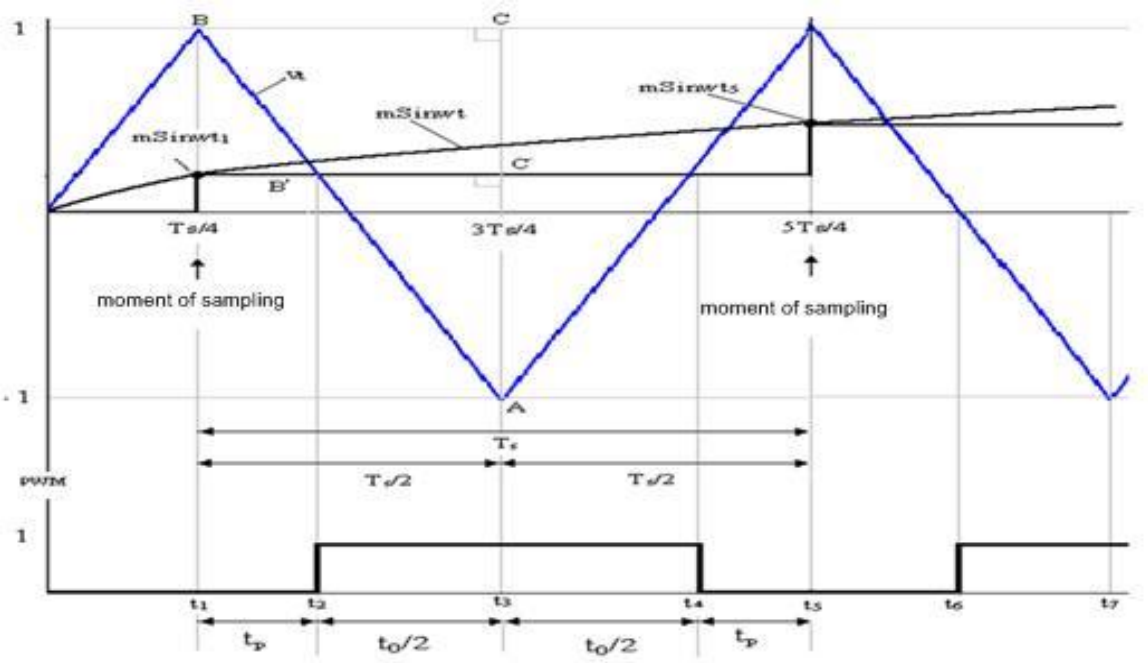

Figure 1. Obtaining a switching signal in symmetric regular sampled SPWM

For the symmetric regular sampled SPWM, the pulse width is calculated by taking advantage of the sampling points of the triangular waveguide with sampled pulses. Using the right triangular similarities in Fig. 1, the transmission and cutting formulas can be derived.

$\mathrm{ABC}$ and $\mathrm{AB}^{\prime} \mathrm{C}^{\prime}$ are found in right triangular similarities [B' $\left.\mathrm{C}^{\prime}\right]$. Here, $t_{o}$ is the transmission period in a switching period. Cut-off time is $2 t_{p}$. Then,

$\mathrm{t}_{\mathrm{o}}=\left(\mathrm{T}_{\mathrm{s}} / 2\right)\left[1+\mathrm{mSinwt}_{1}\right]$

$\mathrm{t}_{\mathrm{p}}=\left(\mathrm{T}_{\mathrm{s}} / 2\right)-\left(\mathrm{t}_{\mathrm{o}} / 2\right)=\left(\mathrm{T}_{\mathrm{s}} / 4\right)\left[1-\mathrm{mSinwt}_{1}\right]$

\section{Simulink Simulation of Sinusoidal PWM with Symmetric Regular Sampling.}

In the symmetric regular sampling sinusoidal PWM method, the sine wave is sampled in the switching period and compared with the triangular wave. This method has been performed simulink as shown in Fig.2.

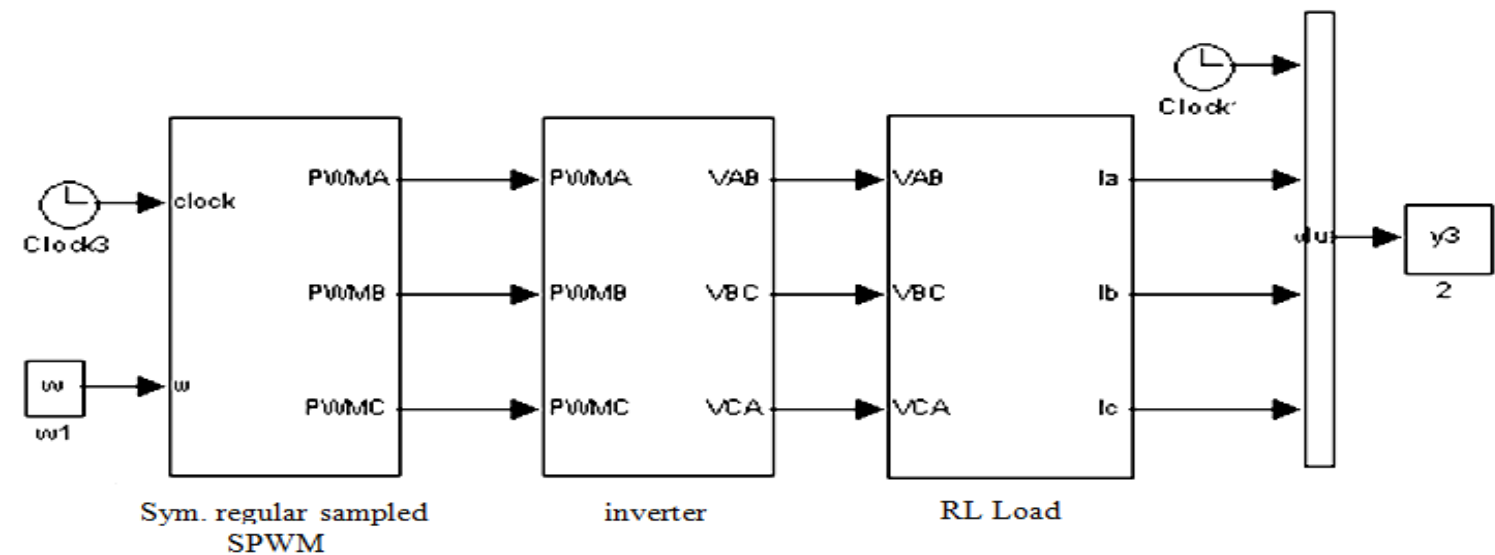

Figure 2. Symmetric regular sampled SPWM Simulink simulation 
The harmonic analysis of the inverter line voltage is performed for the modulation methods simulated. Harmonic analysis was carried out for the values of output frequency $50 \mathrm{~Hz}$, switching frequency $450 \mathrm{~Hz}, 1050 \mathrm{~Hz}, 2000 \mathrm{~Hz} 4500 \mathrm{~Hz}, 17000 \mathrm{~Hz}$ and modulation index 0.3, 0.8 and 2 . Modulation index values of 0.3 and 0.8 were chosen for the linear region and 2 values for over modulation. For the switching frequency, $450 \mathrm{~Hz}$ low frequency, $17000 \mathrm{~Hz}$ high frequency and other values are selected as intermediate values. Thus, the effect of the modulation frequency and the modulation index will be observed for different values. The pole voltage, line voltage and line currents obtained for the RL load from the SPWM method with symmetrical regular sampling are given in Fig. 3. Harmonic analysis results are shown in Figure 4-8..
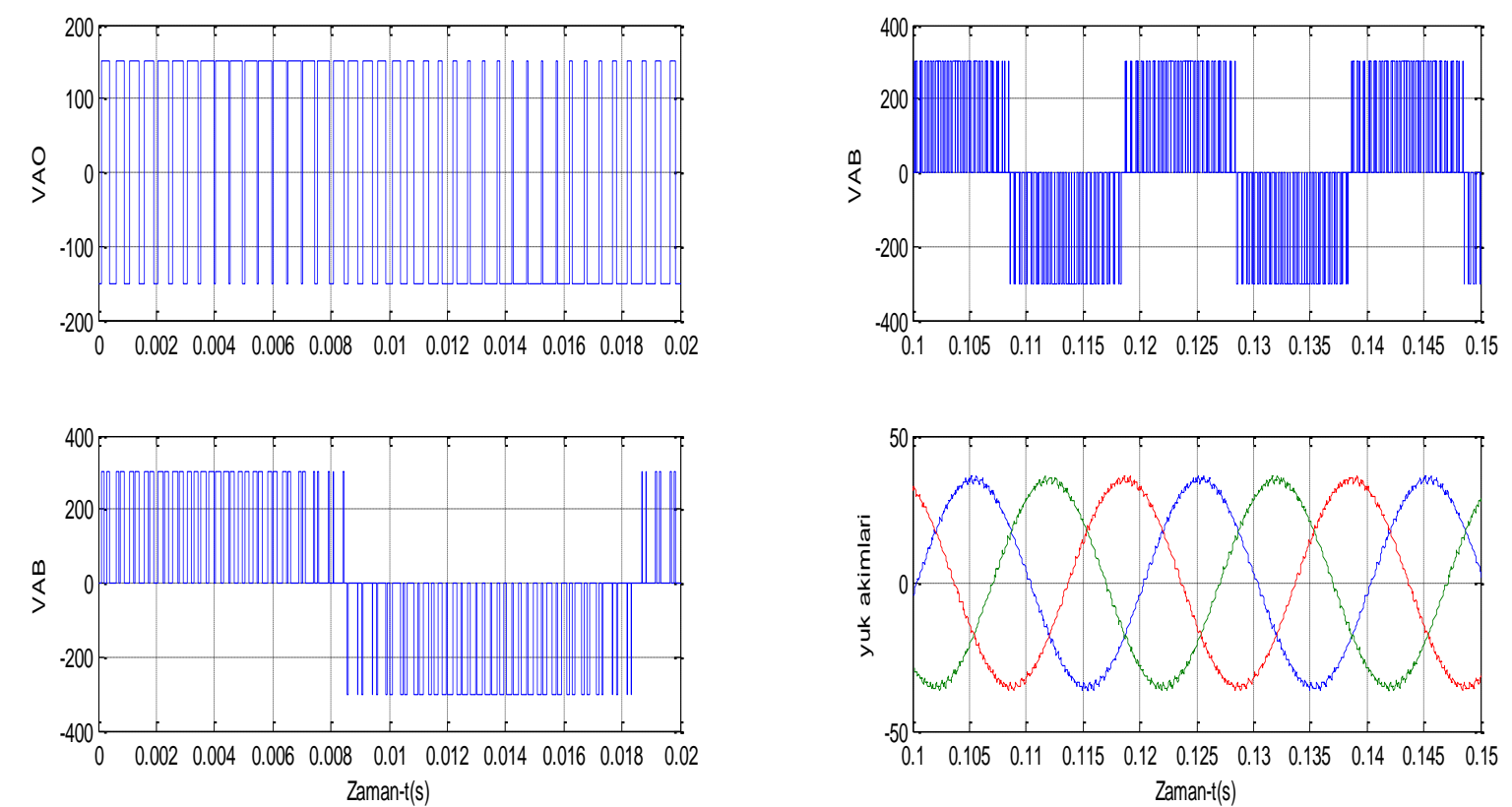

Figure 3. Symmetrical regular sampled SPWM at $f_{s}=4500 \mathrm{~Hz}, \mathrm{~m}_{\mathrm{a}}=0.8$ a) Inverter $\mathrm{V}_{\mathrm{AO}}$ pole voltage and $V_{A B}$ line voltage $b$ ) Inverter $V_{A B}$ line voltage and load currents
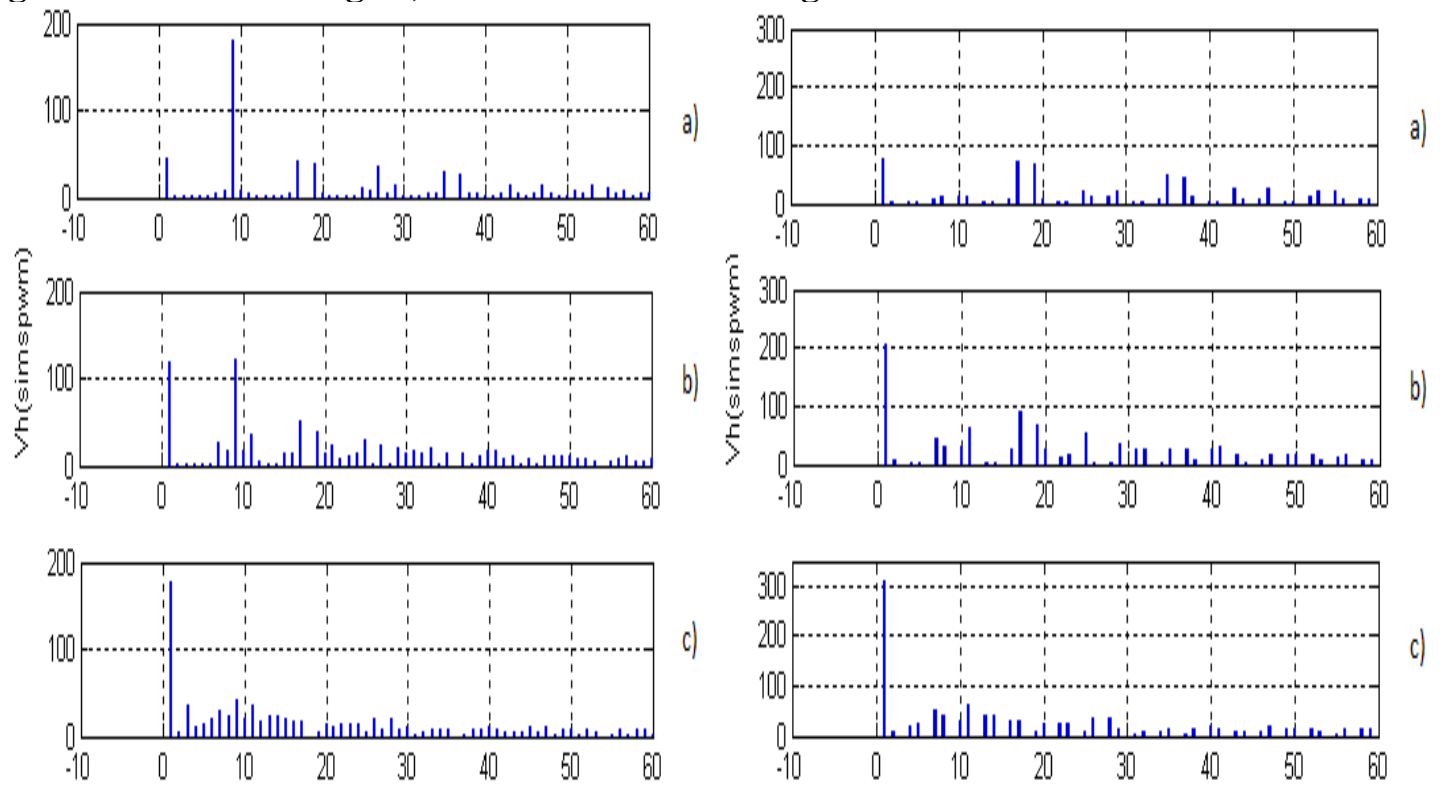

(NAD için)Harmonik Derecesi

(NAD için)Hamornik Derecesi

Figure 4. Harmonic analysis for $\mathrm{V}_{\mathrm{AO}}$ polarity at $\mathrm{f}_{\mathrm{s}}=450 \mathrm{~Hz} \mathrm{~m}_{\mathrm{a}}=0.3,0.8,2$ 

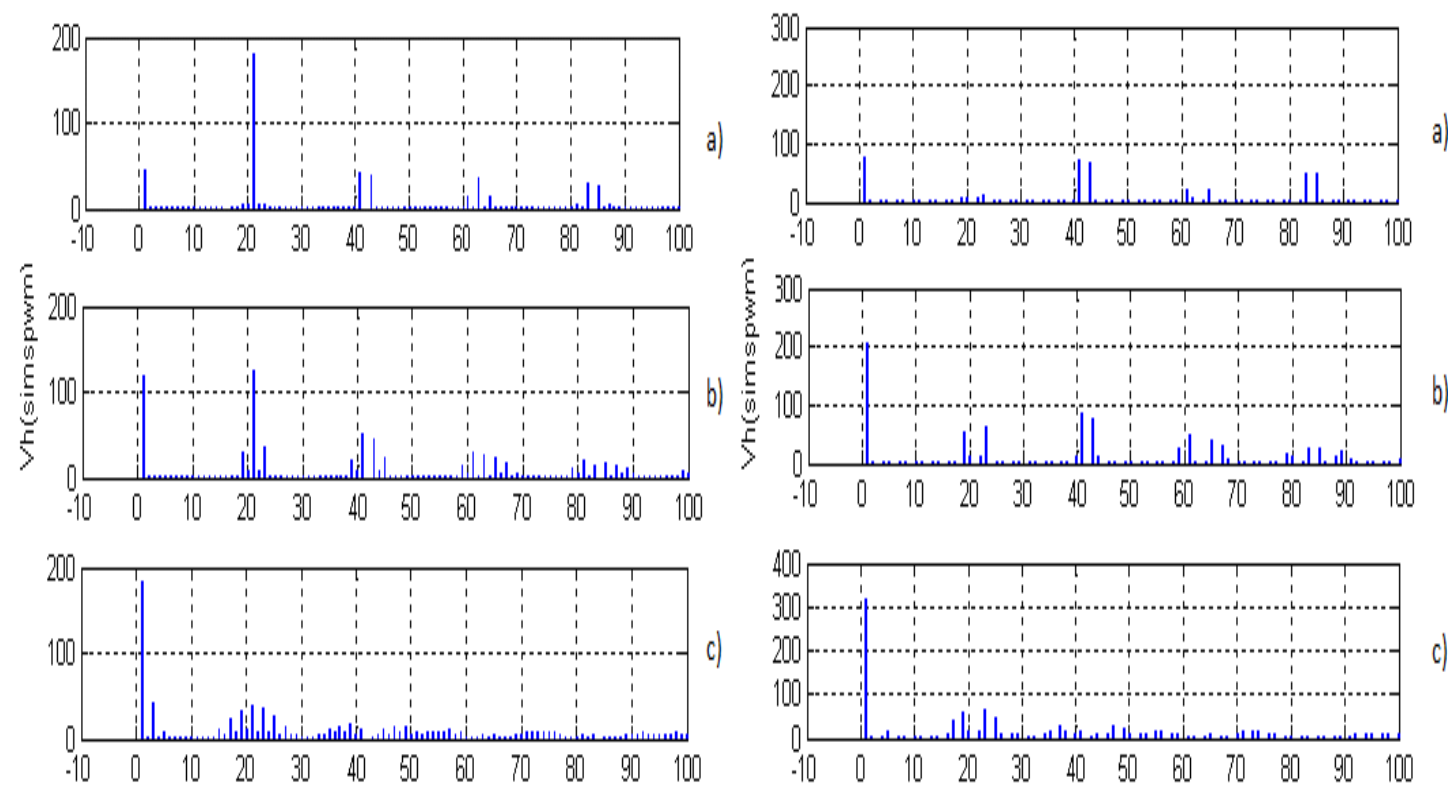

NAD içinj)Harmonik Derecesi

NAD için)Hiharmonik Derecesi

Figure 5. Harmonic analysis for $\mathrm{V}_{\mathrm{AO}}$ pole voltage at $\mathrm{f}_{\mathrm{s}}=1050 \mathrm{~Hz} \mathrm{~m}_{\mathrm{a}}=\mathbf{0 . 3 , 0 . 8 , 2}$
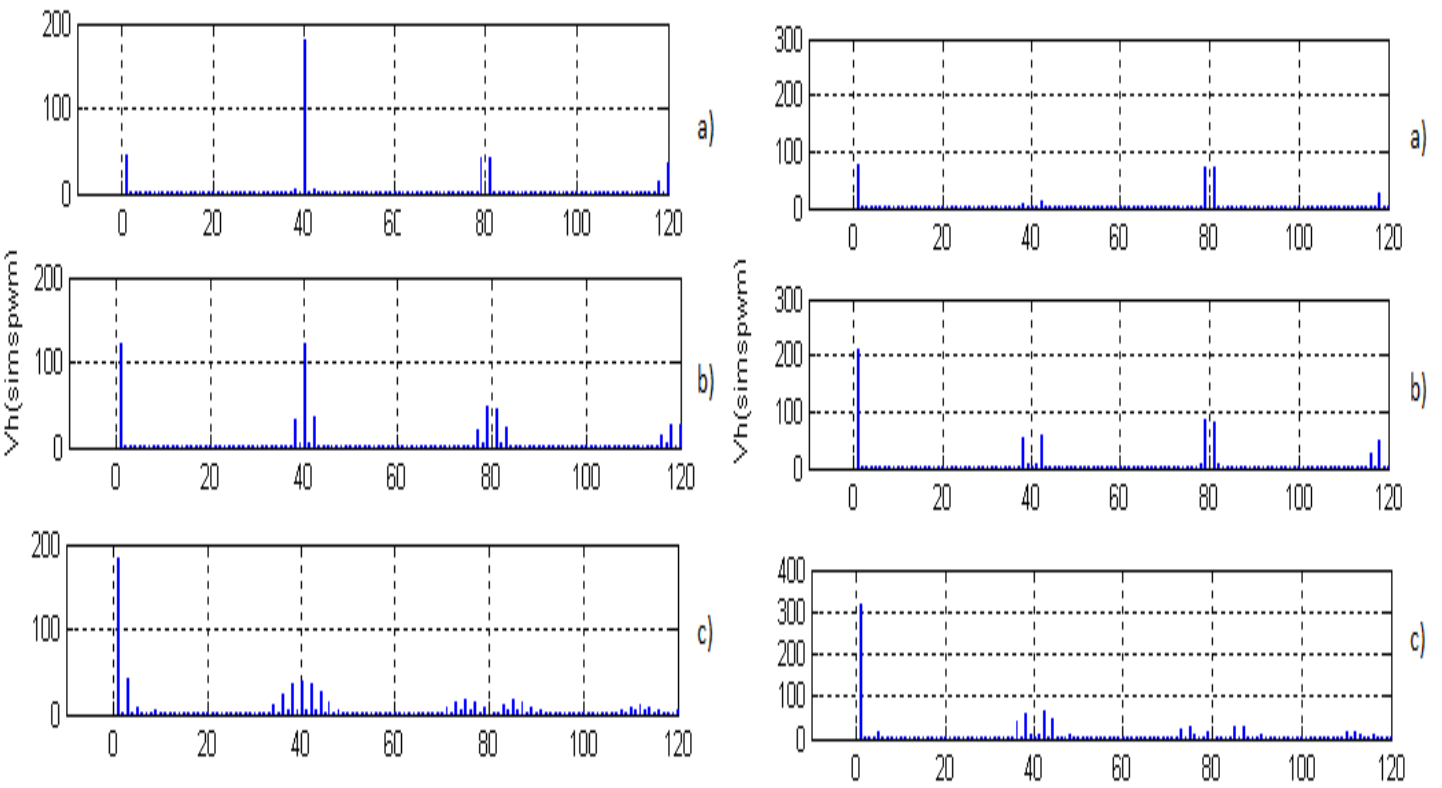

NAD için)H Harmonik Derecesi

NAD için)HHarmonik Derecesi

Figure 6. Harmonic analysis for $V_{A O}$ polarity at $f_{s}=2000 \mathrm{~Hz} m_{a}=0.3,0.8,2$ 

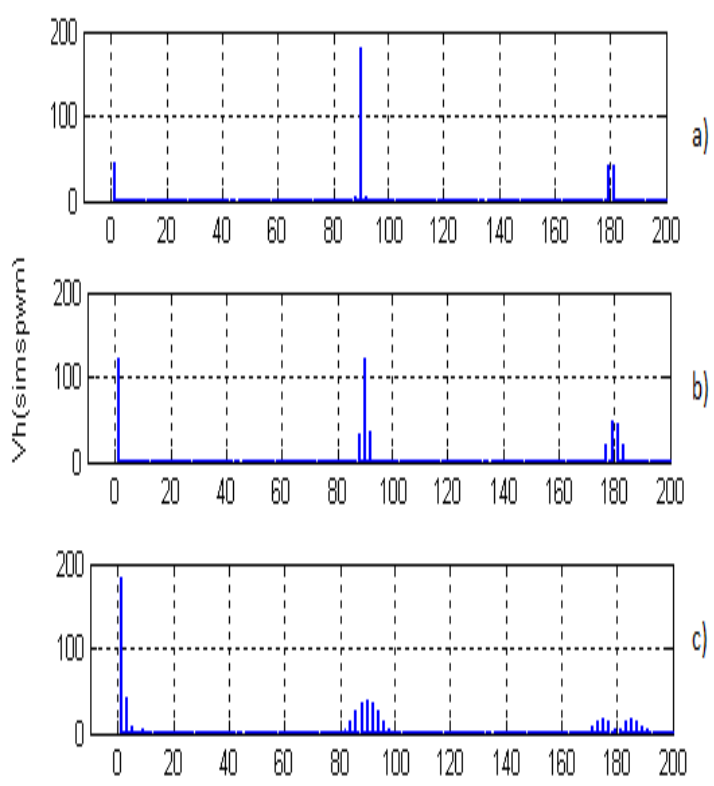

(NAD için)Harmonik Derecesi
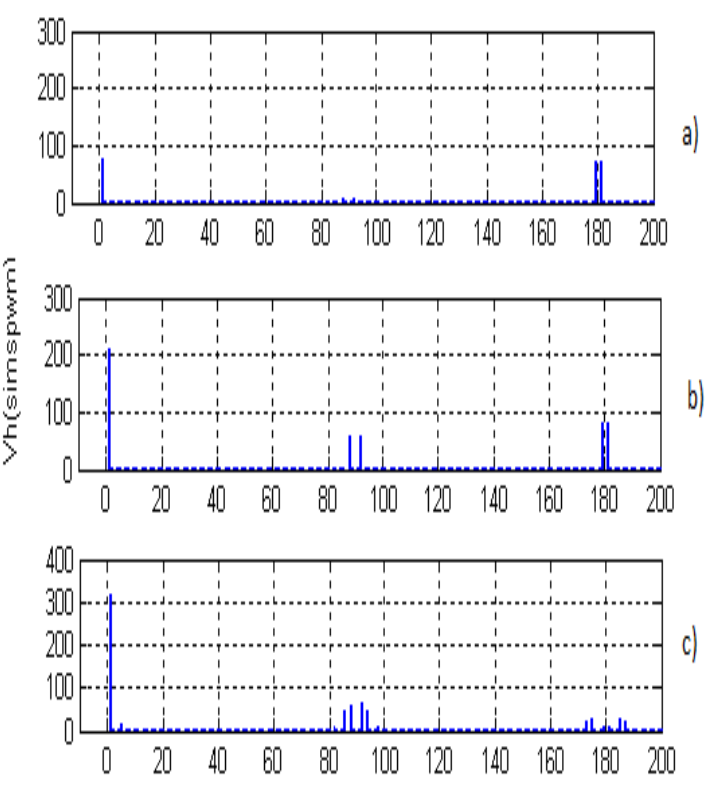

(NAD için)Harmonik Derecesi

Figure 7. Harmonic analysis for $\mathrm{V}_{\mathrm{AO}}$ polarity voltage at $\mathrm{fs}=4500 \mathrm{~Hz} \mathrm{~m}_{\mathrm{a}}=\mathbf{0 . 3 , 0 . 8 , 2}$
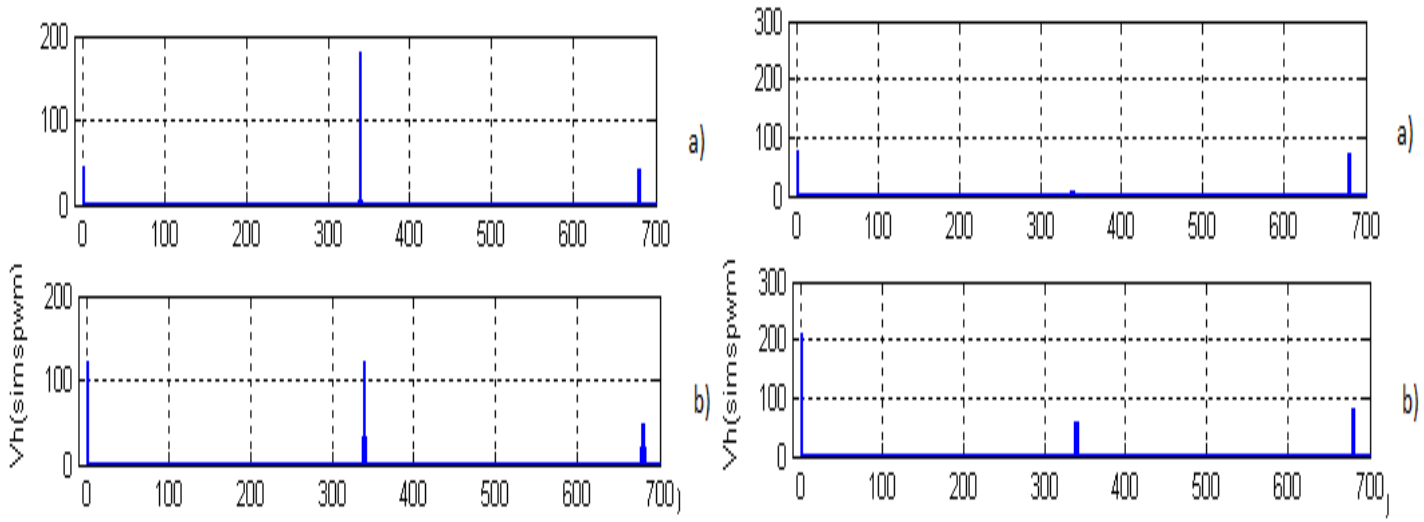

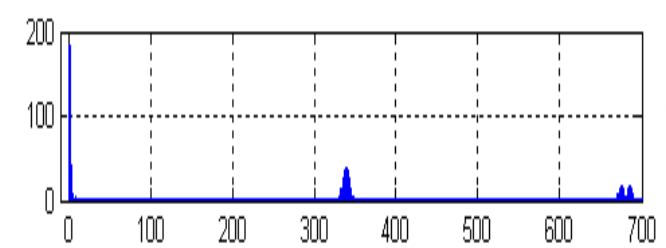

(VAD için)H Harmonik Derecesi

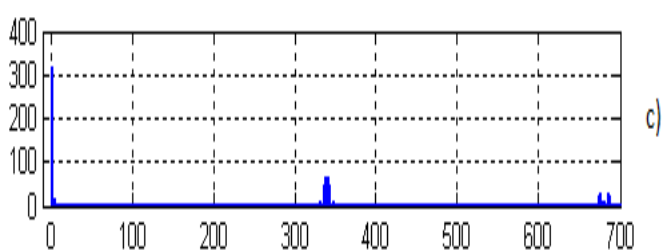

NAD icini)Harmonik Derecesi

Figure 8. Harmonic analysis for $V_{A O}$ pole voltage at $f_{s}=17000 ~ H z ~ m_{a}=0.3,0.8,2$

In this study, the symmetric regular sampled SPWM method is modeled simulink of a RL load in voltage source inverters and the effect of different switching frequency and modulation index is investigated.

In the simulation, firstly polarity voltage, line voltage and load currents graphs are obtained in the linear region. Secondly, harmonic analysis is performed for five different switching frequencies and three different modulation indexes. For both methods, we have observed in all the switching frequencies that the amplitude of the first component in the linear region is proportional to the modulated index, if we make a general assessment. In theory, the harmonics are described in the previous sections where the switching frequency and side bands are formed. This is evident in the graph of harmonic analysis of each linear region. At the same time, it has also been observed that loworder harmonics in the low-switching frequencies move away with increasing frequency. 
The departure of the harmonics means that it is more easily eliminated. But increasing the number of switching increases the switching losses. It is also noted that, at the three switching frequencies, the value of 0.3 for the low values of the linear divider has a very large amplitude of the harmonic generated and the side bands $\left(\mathrm{m}_{\mathrm{f}}+1, \mathrm{~m}_{\mathrm{f}}-1\right)$ are very small. In the over-modulated region $\left(\mathrm{m}_{\mathrm{a}}\right.$ $=2$ ), it is observed that the harmonics that occur in the square wave occur, that is, the harmonics that occur in the side band increase. When the harmonics of $\mathrm{V}_{\mathrm{AO}}$ and $\mathrm{V}_{\mathrm{AB}}$ voltages are examined together, it is seen that some harmonics in $\mathrm{V}_{\mathrm{A} 0}$ are not in $\mathrm{V}_{\mathrm{AB}}$. This is the result of this three-phase system.

\section{Conclusion.}

Theoretically, the modulation index increases while the fundamental component amplitude increases. This is evident in all the results from the conclusions. Expected results were also seen in switching frequency changes.

The symmetric regular sampled method can be described as the digital realization of classical sinusoidal PWM. It is numerical in nature and suitable for digital hardware and microprocessor applications.

\section{References}

[1] Sarığlu, K., Gökaşan,M., Boğosyan,S., “Asenkron Motorlar ve Kontrolu” Birsen yayınları, 2003

[2] Gülgün, R., "Güç Elektroniği’” Yıldız Teknik Üniversitesi Yayınları ,İstanbul 1995

[3] Kaynak,O., "Güç Elektroniği: Elemanlar Devreler ve Sistemler”'Ağutos 1988

[4] Williams, B.W, "Power Elektronics" 1992

[5] Ertan,H.B, Üçtuğ,M.Y, Colyer,C.,Consoli,A. “Modern Elektrical Drives" 1994

[6] Skvarenina, T.L., "Power elektronics handbook" CRC press, 2002

[7] Xiao-ling W., Xiang-gen Y., "The Unified PWM İmplementation Metod for Three-Phase İnverter" Second IEEE Conference on İndustrial Electronics and Aplication, 2007

[8] Narayanan,N., Ranganathan, V:T., " Overmodulaton algoritma for space vector modulated inverters and its application to low switching frequency PWM tecniniques" IEE proc.-electr. Power appl. 148,6,November 2001

[9] Kentli, F., \& Yilmaz, M. (2015). Mathematical modelling of two-axis photovoltaic system with improved efficiency. Elektronika ir Elektrotechnika, 21(4), 40-43.

[10] Zeng,Q., Chang,L.,Song,P., "SVPWM-based current controller with grid harmonic compensation for three-phase grid-connected VSI" 2004 35th anunual power Electroniks Specialist conferance" Aachen,Germany, 2004

[11] Chen.,Y., Tong, Y. Jin.,X., “A Novel Algorithm of SVPWM Harmonik Analysis" Second IEEE Conference on İndustrial Electronics and Aplication, 2007

[12] Bose,B.K, “Modern Power Elektronics and AC Drivers"' Prentice-hall, 2002

[13] Rashid,M.H., "Power Elektronics Handbook” Academic press, 2001 